\title{
Biosynthesis of Ergotamine in Protoplasts of Claviceps purpurea
}

\author{
By ULLRICH KELLER,* RAINER ZOCHER AND HORST KLEINKAUF \\ Max-Volmer-Institut, Technische Universität Berlin, Abteilung Biochemie, \\ Franklinstrasse 29, D 1000 Berlin 10, Germany
}

(Received 19 September 1979; revised 28 November 1979)

\begin{abstract}
Protoplasts of Claviceps purpurea (ATCC 20102) were prepared in $0 \cdot 8 \mathrm{M}$-sucrose containing $10 \mathrm{mM}-\mathrm{CaCl}_{2}$ and $10 \mathrm{~mm}-\mathrm{MgCl}_{2}$. Protoplasts could revert to the filamentous state but not after treatment with water. Most of the protoplasts (about $80 \%$ ) were highly vacuolated and these were separated from the non-vacuolated protoplasts and cell debris on the basis of their low density. Only the vacuolated protoplasts were able to synthesize ergotamine and ergocryptine de novo. Protoplasts were about $50 \%$ less active than the control mycelium. The control mycelium was more active in the uptake of labelled precursors than both protoplasts and freshly harvested mycelium. In the amino acid pool of protoplasts, alanine was present in a concentration which exceeded that of proline by a factor of six and that of phenylalanine by a factor of 100 . This finding is consistent with the incorporation ratios of these amino acids into ergotamine when isotope dilution of the added radiolabel is considered. A significant stimulation of incorporation of constituent amino acids into ergotamine and ergocryptine occurred when D-lysergic acid was added to protoplasts and mycelium.
\end{abstract}

\section{INTRODUCTION}

The alkaloids of the ergotamine and ergotoxine group are produced by members of the genus Claviceps (Gröger, 1975). They consist of a cyclic arrangement of three different amino acids, in which an $\alpha$-hydroxy amino acid has undergone cyclol formation with the carboxyl group of a $C$-terminal proline. The latter amino acid is situated within a lactam ring formed together with the second amino acid in the chain. The amino group of the $N$-terminus is attached to the carboxyl group of D-lysergic acid. The amino acids present in the chain characterize the different peptide alkaloids (Fig. 1).

These compounds are synthesized either by sclerotia on ears of rye, or under saprophytic conditions in submerged culture (Amici et al., 1969). Studies of the biosynthesis of these alkaloids have been reviewed elsewhere (Floss, 1976). Nearly all the knowledge concerning the formation and regulation of this important class of peptides stems from feeding experiments with whole mycelium. Only the origin of the ergoline ring moiety from tryptophan and dimethylallylpyrophosphate seems to be established at an enzymic level (Heinstein et al., 1971; Gröger \& Sajdl, 1972). The cell-free synthesis of the ergot peptides from their constituent amino acids and D-lysergic acid has not yet been accomplished.

This lack of a cell-free system may be attributed to denaturing effects during the disintegration of the organism or to the need for an intact cell or organelle structure, which is destroyed during mechanical rupture. Therefore, it seemed desirable to develop a method for enzymic removal of the wall resulting in the formation of protoplasts, since these are much more easily disrupted than intact mycelium and hence are more likely to yield active enzyme preparations. As a prerequisite to the study of cell-free systems from protoplast lysates it is necessary to have protoplast preparations which are actively synthesizing ergot peptides. 
<smiles>CN1CC(C(=O)NC2(C)CN3C(Cc4ccccc4)C(=O)N4CCCC4C3(O)O2)C=C2c3cccc4[nH]cc(c34)CC21</smiles>

Fig. 1. Structural formula of ergotamine. Replacement of the $\alpha$-hydroxyalanyl moiety by $\alpha$-hydroxyvaline and of phenylalanine by leucine gives ergocryptine.

The preparation of protoplasts from Claviceps purpurea has been reported previously (Stahl et al., 1977; Spalla et al., 1976) but these were not tested for alkaloid formation. We have studied the formation of protoplasts derived from C. purpurea and the conditions required to keep them active with respect to ergotamine synthesis. Aspects of the physiology of alkaloid formation in this fungus were also considered.

\section{METHODS}

Growth of organism. Claviceps purpurea (ATCC 20102) was maintained on agar slants of medium T2 as described previously (Amici et al., 1967). Portions $\left(1 \mathrm{~cm}^{2}\right)$ of the mycelial mat of $C$. purpurea, from Petri dishes grown for 2 weeks at $25^{\circ} \mathrm{C}$, were placed into $300 \mathrm{ml}$ conical flasks containing $60 \mathrm{ml}$ inoculum medium (Amici et al., 1966). Flasks were then incubated for up to $9 \mathrm{~d}$ at 27 to $28^{\circ} \mathrm{C}$ in a New Brunswick Environmental Shaker (at 220 rev. $\mathrm{min}^{-1}$, diam. of rotation $2 \cdot 5 \mathrm{~cm}$ ).

Preparation of protoplasts. All operations were carried out at 20 to $25^{\circ} \mathrm{C}$ (protoplasts were damaged below $15^{\circ} \mathrm{C}$ and above $30^{\circ} \mathrm{C}$ ). The mycelia of $8 \mathrm{~d}$-old cultures (grown as described above) were harvested by suction on a Büchner funnel and washed extensively with $0.4 \mathrm{M}$-sucrose. When excess water had been removed, portions $(2.5 \mathrm{~g})$ were placed, under sterile conditions, into $100 \mathrm{ml}$ conical flasks containing $25 \mathrm{ml}$ protoplast medium (PM) consisting of $0.8 \mathrm{M}$-sucrose, $10 \mathrm{mM}$-sodium citrate ( $\mathrm{pH} 4.7), 10 \mathrm{~mm}-\mathrm{MgCl}_{2}$ and $10 \mathrm{mM}-\mathrm{CaCl}_{2}$. After careful homogenization, $1.2 \mathrm{ml} \beta$-glucuronidase from Helix pomatia was added and the mixture was incubated for $12 \mathrm{~h}$ at $26^{\circ} \mathrm{C}$ in a New Brunswick Environmental Shaker (at $120 \mathrm{rev}$. $\mathrm{min}^{-1}$ ). Following incubation, the $A_{650}$ of the protoplast suspension was determined, after which it was diluted threefold with PM and filtered through glass wool to remove large mycelial fragments. The filtered suspension was centrifuged in swing-out buckets $(5000 \mathrm{~g}, 20 \mathrm{~min})$ and the top layers of highly vacuolated floating protoplasts were collected in a test tube. The supernatants were discarded and the pellets containing non-vacuolated protoplasts and small mycelial fragments, in which some vacuolated protoplasts were trapped, were resuspended in one-fifth of the original volume. This procedure was repeated and the combined layers of floating vacuolated protoplasts were washed by resuspension and centrifugation in an appropriate volume of PM. Purified protoplasts were counted under the phase contrast microscope in a counting chamber. The suspension was adjusted to $3 \times 10^{9}$ to $4 \times 10^{9}$ protoplasts $\mathrm{ml}^{-1}\left(A_{650}=60\right)$. Serial dilutions of the protoplast suspensions, in PM or water, were spread on Petri dishes with nutrient agar (Amici et al., 1967) containing 0.6 M-sucrose, to examine the nature of the protoplasts.

Experimentation with the protoplasts proceeded immediately after their preparation, except when samples of the protoplast suspensions were frozen for subsequent analysis of the anino acid pool.

Detection of ergot peptide synthesis. Ergot peptide synthesis was followed by adding radioactive precursors to protoplasts or control mycelium and subsequently isolating radioactively labelled alkaloids. Samples $(200 \mu 1)$ of the prepared protoplast suspension were placed in test tubes $(12 \times 120 \mathrm{~cm})$ with a final volume of $1.0 \mathrm{ml} \mathrm{PM}$, containing $2 \mu \mathrm{Ci}(74 \mathrm{kBq})$ of the relevant radioisotope. Other compounds tested (kept as $0.1 \mathrm{M}$ solutions or suspensions in PM) were present at concentrations indicated in the text. The control mycelium was treated as follows: $1.0 \mathrm{ml}$ samples ( 75 to $80 \mathrm{mg}$ wet wt) of a mycelial suspension, which were treated in the same way as the protoplast preparation but with the omission of $\beta$-glucuronidase, were filtered through glass-fibre filters under suction and resuspended in a final volume of $1.0 \mathrm{ml}$ of PM. Tubes containing protoplasts and mycelial samples were incubated at $28^{\circ} \mathrm{C}$ in a New Brunswick Environmental Shaker (at 350 rev. $\left.\min ^{-1}\right)$. 
After incubation the tubes were frozen at $-32{ }^{\circ} \mathrm{C}$ in the dark and then analysed. All operations were carried out to minimize the action of light and heat on the samples. An equal volume of $4 \%(\mathrm{w} / \mathrm{v})$ tartaric acid, two volumes of acetone and $10 \mu \mathrm{l}\left(1 \mathrm{mg} \mathrm{ml}^{-1}\right)$ of carrier ergotamine or ergocryptine were added to the samples and mixed thoroughly (Amici et al., 1969). The mixtures were kept in the dark at $4{ }^{\circ} \mathrm{C}$ for $30 \mathrm{~min}$. Saturated aqueous $\mathrm{Na}_{2} \mathrm{CO}_{3}$ solution was then added to bring the $\mathrm{pH}$ to $8 \cdot 5$. The samples were extracted twice with $2 \mathrm{ml}$ chloroform, the combined extracts were dried at $25^{\circ} \mathrm{C}$ in a rotary evaporator and each residue was taken up in $50 \mu \mathrm{l}$ chloroform/methanol $(1: 1, \mathrm{v} / \mathrm{v})$ and applied to a silica gel sheet which was developed in the dark with solvent system I (see below). After development, the sheets were dried with a stream of cold air and the alkaloids were located by their fluorescence in ultraviolet light. Radioactive zones were detected and analysed as described below.

Uptake of amino acids by protoplasts and mycelium. The uptake of amino acids was measured by the disappearance of the ${ }^{14} \mathrm{C}$-labelled amino acids from the medium. After various time intervals parallel samples of protoplasts and control mycelium were centrifuged and the radioactivity of the medium was measured.

Analysis of the amino acid pool of protoplasts. Analysis was done as described previously (Keller \& Kleinkauf, 1977 ), i.e. $200 \mu \mathrm{l}$ of the protoplast suspension $\left(A_{650}=60\right)$ was diluted 20 -fold with distilled water, adjusted to $\mathrm{pH} 2$ with $1 \mathrm{M}-\mathrm{HCl}$ and heated in a water bath at $100{ }^{\circ} \mathrm{C}$ for $10 \mathrm{~min}$. The suspension was then centrifuged at $20000 \mathrm{~g}$ for $20 \mathrm{~min}$ and the supernatant was applied to a small Dowex- 50 column $\left(\mathrm{H}^{+}\right.$form $)$from which the amino acids were eluted with $2 \mathrm{M}$-pyridinium acetate. The eluate was dried by evaporation and analysed with a Durrum amino acid analyser. A control run was made with similar material which had been hydrolysed previously in $5.6 \mathrm{M}-\mathrm{HCl}$ at $105^{\circ} \mathrm{C}$ for $22 \mathrm{~h}$.

Analytical methods. Ergot peptides were separated by thin-layer chromatography on silica gel sheets (Merck). The solvent systems used were: I, ethyl acetate/dimethylformamide/ethanol (65:9.5:0.5, by vol.) (Amici et al., 1969); II, ethyl acetate/methanol $(19: 1, \mathrm{v} / \mathrm{v}) \cdot($ Gröger et al., 1974); III, chloroform/methanol/ ammonia (80:20:0·2, by vol.) (Amiciet al., 1969). Hydrolysis was performed in sealed tubes with $5 \cdot 6 \mathrm{M}-\mathrm{HCl}$ at $105^{\circ} \mathrm{C}$ for $22 \mathrm{~h}$. Amino acid analysis of the hydrolysates was done by thin-layer chromatography with various solvent systems (Keller \& Kleinkauf, 1977). Amino acids were visualized with ninhydrin spray or, when labelled, they were detected with a Berthold radioscanner or by autoradiography using Agfa X-ray film. Measurements were made by scraping the radioactive zone off the plates, extracting three times with chloroform/methanol $(1: 1, \mathrm{v} / \mathrm{v})$ and counting with a Packard Tri-Carb liquid scintillation spectrophotometer in Bray's solution (Bray, 1960).

Radioisotopes and chemicals. L-[U-14 $\mathrm{C}] \mathrm{Phenylalanine}\left(513 \mathrm{Ci} \mathrm{mol}^{-1}, 19 \mathrm{TBq} \mathrm{mol}^{-1}\right)$, L-[U-- $\left.{ }^{14} \mathrm{C}\right]$ proline $\left(290 \mathrm{Ci} \mathrm{mol}^{-1}, 10 \cdot 7 \mathrm{TBq} \mathrm{mol}{ }^{-1}\right), \mathrm{L}-\left[\mathrm{U}_{-}{ }^{14} \mathrm{C}\right]$ alanine $\left(171 \mathrm{Ci} \mathrm{mol}^{-1}, 6 \cdot 3 \mathrm{TBq} \mathrm{mol}^{-1}\right)$, L-[U- $\left.{ }^{14} \mathrm{C}\right]$ valine $(295 \mathrm{Ci}$ $\left.\mathrm{mol}^{-1}, 10 \cdot 9 \mathrm{TBq} \mathrm{mol}^{-1}\right)$ and $\mathrm{L}-\left[\mathrm{U} \cdot{ }^{-19} \mathrm{C}\right] \mathrm{leucine}\left(340 \mathrm{Ci} \mathrm{mol}^{-1}, 12.6 \mathrm{TBq} \mathrm{mol}^{-1}\right)$ were from The Radiochemical Centre, Amersham. Ergotamine tartrate, ergocryptine sulphate and D-lysergic acid (grade II) were obtained from Sigma and $\beta$-glucuronidase (Helix pomatia) from Merck.

\section{RESULTS}

\section{Formation and properties of protoplasts of Claviceps purpurea}

Phase contrast microscopy showed that mycelium of $C$. purpurea incubated in PM containing $\beta$-glucuronidase released protoplasts after $1 \mathrm{~h}$ and release was complete within 8 to $10 \mathrm{~h}$ when the mycelium was completely disintegrated. Mycelium incubated under the same conditions but without $\beta$-glucuronidase did not show any changes in appearance. The protoplast suspension consisted of protoplasts of differing size and appearance and of small mycelial fragments of similar size to the protoplasts. Purified protoplasts, after fractionation, are shown in Fig. 2.

The fact that the size of mycelial fragments was in the same range as that of protoplasts made it possible to use the $A_{650}$ of the non-fractionated protoplast suspension as a quantitative measurement. In eight separate experiments, the non-fractionated suspension had an absorbance of 14 to 16 at the end of the incubation period in the presence of snail enzyme.

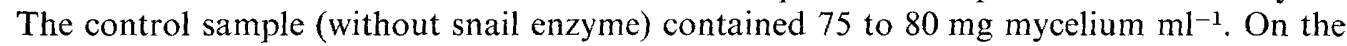
basis of the $A_{650}$ it was estimated that $80 \%$ of the sample consisted of vacuolated protoplasts. Phase contrast microscopy revealed that an $A_{650}$ value of 15 corresponded to about $10^{9}$ cells $\mathrm{ml}^{-1}$ and therefore $1 \mathrm{ml}$ of mycelial suspension $\left(80 \mathrm{mg} \mathrm{ml}^{-1}\right)$ was equivalent to $1 \mathrm{ml}$ of the purified protoplast suspension at an $A_{650}$ value of 12 .

Serial dilutions of floating protoplast suspensions $\left(A_{650}=60\right)$, in either PM or water, were spread on to plates of medium T2 $(0.6 \mathrm{M}$-sucrose $)$ to examine their osmotic fragility 


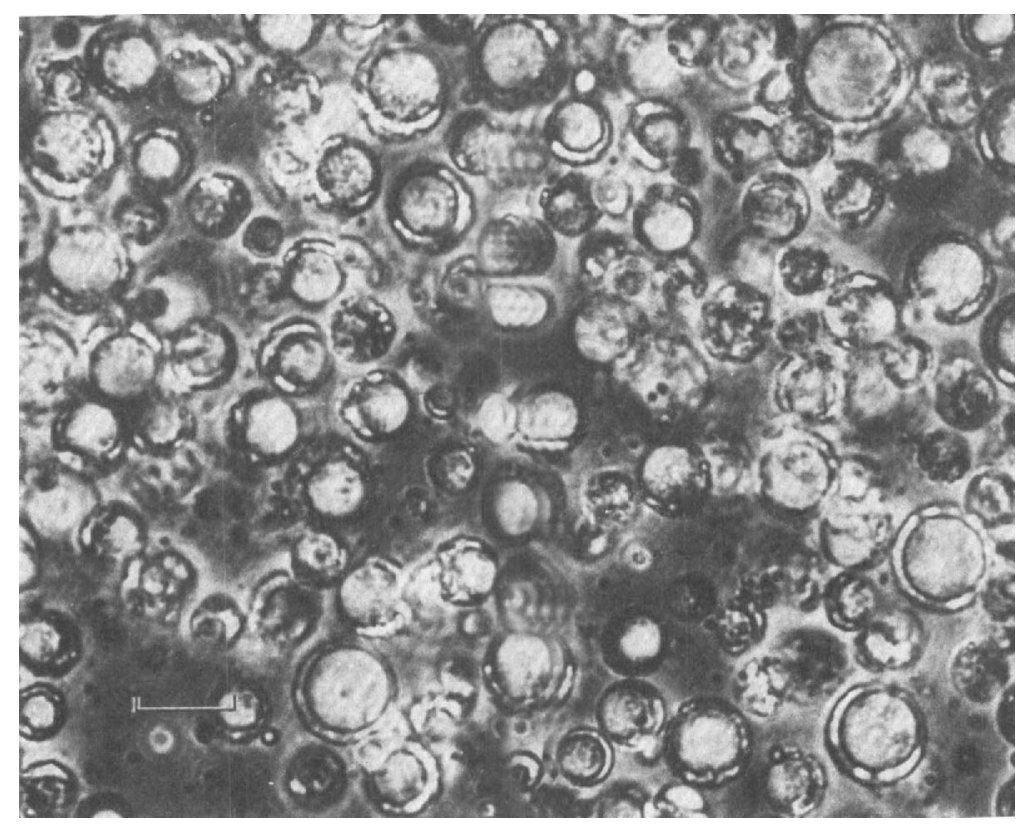

Fig. 2. Photomicrograph of purified protoplasts of Claviceps purpurea. Bar marker represents $10 \mu \mathrm{m}$.

and reversion ability. Dilutions with PM showed incipient mycelial growth after $3 \mathrm{~d}$. Normal colonies appeared after $8 \mathrm{~d}$ and these were able to synthesize ergot alkaloids when grown in liquid culture. Dilutions with water showed no growth indicating that the seeded cells, presumably protoplasts, were osmotically fragile. The reversion frequencies measured were 4 to $8 \%$ of total counts.

\section{Ergot peptide synthesis in protoplasts}

Purified vacuolated protoplasts from $C$. purpurea were incubated in the presence of $\left[{ }^{14} \mathrm{C}\right]$ phenylalanine, $\left[{ }^{14} \mathrm{C}\right]$ alanine or $\left[{ }^{14} \mathrm{C}\right]$ proline. Using $\left[{ }^{14} \mathrm{C}\right]$ phenylalanine a significant incorporation into ergotamine by protoplasts and mycelium was demonstrated. Ergotamine was identified by thin-layer chromatography in solvent systems I, II and III and subsequent hydrolysis of the corresponding fluorescent band. No formation of radioactive ergocryptine was observed when protoplasts were incubated with $\left[{ }^{14} \mathrm{C}\right]$ valine, $\left[{ }^{14} \mathrm{C}\right]$ proline or $\left[{ }^{14} \mathrm{C}\right]$ leucine. Under the conditions described, the formation of radioactive ergotamine from ergotamine was negligible and the hydrolysis of ergotamine synthesized from $\left[{ }^{14} \mathrm{C}\right]$ phenylalanine yielded exclusively $\left[{ }^{14} \mathrm{C}\right]$ phenylalanine.

The amount of radioactive alkaloid formed was low. After $4 \mathrm{~h}$ incubation in the presence of $\left[{ }^{14} \mathrm{C}\right]$ phenylalanine, protoplasts had synthesized ergotamine containing only 1100 c.p.m. whereas mycelium had incorporated 4000 c.p.m. $\left[{ }^{14} \mathrm{C}\right]$ Proline yielded about 400 and 1000 c.p.m. in ergotamine from protoplasts and mycelium, respectively. $\left[{ }^{14} \mathrm{C}\right]$ Alanine was not incorporated into ergotamine. Interestingly, the amount of radioactive ergot peptide from incubations with fresh mycelium (incubated immediately after harvest) was only $30 \%$ of that from control mycelium, with both $\left[{ }^{14} \mathrm{C}\right]$ phenylalanine and $\left[{ }^{14} \mathrm{C}\right]$ proline. This was also true when D-lysergic acid was present (see below).

In similar experiments with the pellet of the protoplast preparations no radioactive ergot peptide was detected.

Experiments to determine the effect of shaking the tubes containing the cell suspensions showed that shaking at high frequencies gave the best incorporation of $\left[{ }^{14} \mathrm{C}\right]$ phenylalanine 


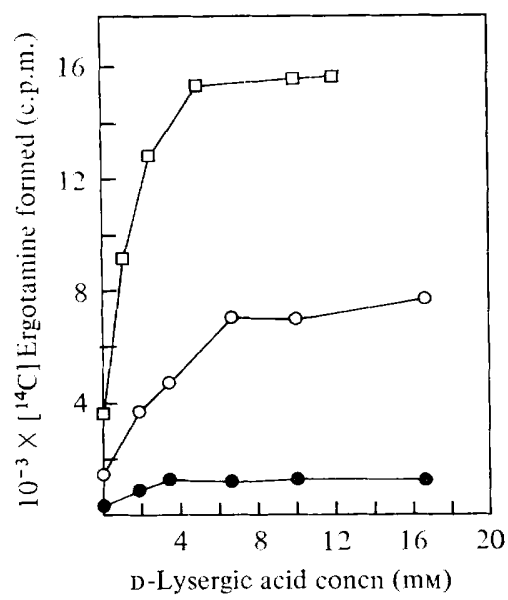

Fig. 3

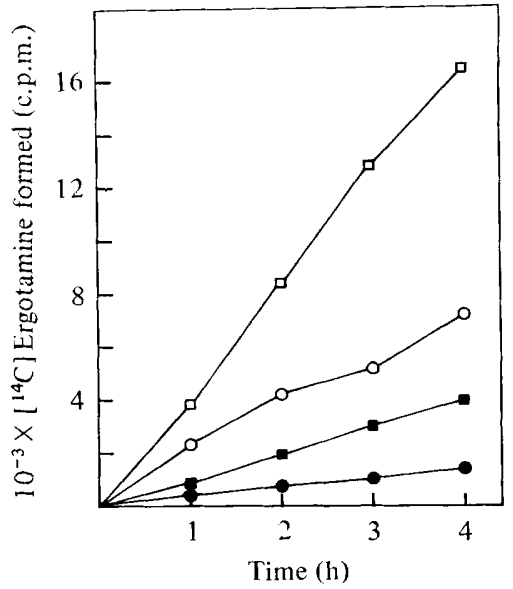

Fig. 4

Fig. 3. Dependence of ergotamine synthesis on D-lysergic acid concentration in incubations with protoplasts and control mycelium: $O$, incorporation of $\left[{ }^{14} \mathrm{C}\right]$ phenylalanine into ergotamine by protoplasts; $\boldsymbol{O}$, incorporation of $\left[{ }^{14} \mathrm{C}\right]$ proline into ergotamine by protoplasts; $\square$, incorporation of $\left[{ }^{14} \mathrm{C}\right]$ phenylalanine into ergotamine by control mycelium.

Fig. 4. Time course of $\left[{ }^{14} \mathrm{C}\right]$ phenylalanine incorporation into ergotamine in protoplasts and control mycelium; $O$, protoplasts with and without $D$-lysergic acid, respectively; $\square, \square$, control mycelium with and without $\mathrm{D}$-lysergic acid, respectively.

into alkaloid. Under static conditions no radioactive alkaloid was formed. This effect was also observed when D-lysergic acid was present during incubation (see below).

\section{Influence of external precursors}

Since the incorporation of radioactive precursors into ergotamine was poor, especially in the case of alanine and proline, we tried to stimulate synthesis by the addition of excess unlabelled precursors, namely, phenylalanine, alanine, proline and D-lysergic acid. For example, the influence of a high proline concentration was measured in the presence of $\left[{ }^{14} \mathrm{C}\right]$ phenylalanine and vice versa. Only the addition of D-lysergic acid produced a significant stimulation. Figure 3 shows the effect of increasing concentrations of D-lysergic acid on ergotamine synthesis in protoplast suspensions. Stimulation of $\left[{ }^{14} \mathrm{C}\right]$ phenylalanine and $\left[{ }^{14} \mathrm{C}\right]$ proline incorporation increased up to a concentration of about $6 \mathrm{~mm}$-D-lysergic acid but did not increase further at higher concentrations. This effect was also observed in incubations with control mycelium (Fig. 3) but the extent of stimulation was less pronounced. In addition, there was a significant incorporation of $\left[{ }^{14} \mathrm{C}\right]$ valine into ergocryptine which was not observed in the absence of D-lysergic acid. The labelled ergocryptine was identified by thin-layer chromatography in the three solvent systems. An amino acid analysis was not carried out due to the small amount of radioactivity present.

The formation of ergotamine by protoplasts with and without D-lysergic acid proceeded linearly with time (Fig. 4). A similar effect was observed with the control mycelium.

\section{Amino acid pool of protoplasts}

The poor incorporation of proline and alanine into ergotamine by protoplasts, compared with the incorporation of phenylalanine, raised the question of whether or not differences in intracellular concentrations of the free amino acids were responsible for this effect. The analysis of the amino acid pool of the protoplasts of C. purpurea is shown in Table 1 . Of the amino acid precursors of ergot peptides, alanine was present in the highest concentration. The concentration of proline was one-sixth and that of phenylalanine was only about one- 
Table 1. Composition of amino acid pools of protoplasts of $C$. purpurea

Results show the amounts of the various amino acids in $200 \mu$ protoplast suspension $\left(A_{650}=60\right)$.

$\begin{array}{lc}\text { Amino acid } & \begin{array}{c}\text { Amount } \\ \text { (nmol) }\end{array} \\ \text { Aspartic acid } & 181 \\ \text { Threonine } & 442 \\ \text { Serine } & 158 \\ \text { Glutamic acid } & 633 \\ \text { Proline } & 262 \\ \text { Glycine } & 156 \\ \text { Alanine } & 1497 \\ \text { Valine } & 44 \\ \text { Methionine } & 1 \cdot 8 \\ \text { Isoleucine } & 21 \\ \text { Leucine } & 37 \\ \text { Tyrosine } & 16 \\ \text { Phenylalanine } & 16\end{array}$

hundredth that of alanine. The concentrations of leucine and valine, which are precursors of ergocryptine, were low. Methionine, which serves as a methyl donor for the amino group of D-lysergic acid (Floss, 1976), was the amino acid of lowest concentration in the pool.

\section{Uptake of labelled precursors}

To investigate the possibility that the low incorporation of the amino acids was due to a partial inability to penetrate the cell, uptake studies were undertaken. Figure 5 shows the uptake of phenylalanine by protoplasts and mycelium. The results indicate that the amino acid was taken up by both protoplasts and control mycelium, although the rate of uptake in the control mycelium was higher. After $90 \mathrm{~min}, 92 \%$ of the total radioactivity added had been taken up whereas the protoplasts had incorporated only $42 \%$. The same experiment with fresh mycelium [i.e. mycelium suspended in PM $(1 \mathrm{~g}$ in $10 \mathrm{ml})$ and tested directly after harvesting from the culture] showed a lower rate of uptake, similar to that of the protoplasts. In similar experiments with $\left[{ }^{14} \mathrm{C}\right]$ proline and $\left[{ }^{14} \mathrm{C}\right]$ alanine (results not shown), these two amino acids were efficiently taken up by the cells. Alanine was most rapidly incorporated by protoplasts, control mycelium and fresh mycelium.

\section{Effect of externally added tryptophan and methionine}

Tryptophan and methionine serve as precursors of D-lysergic acid via the elymoclavine pathway in C. purpurea (Bassett et al., 1973; Floss, 1976). We therefore investigated the influence of these two amino acids on ergot peptide synthesis in the protoplasts and the mycelium. When the protoplasts and control mycelium were incubated in the presence of increasing concentrations of either tryptophan or methionine a decrease in ergotamine synthesis was observed. The same result was obtained when these amino acids were tested in the presence of D-lysergic acid (Table 2).

\section{Dependence of protoplasts on sucrose concentration}

From the results of the serial dilutions of the protoplasts in PM and water, it was expected that lowering the sucrose concentration of PM would reduce the amount of alkaloid formed by protoplasts. Experiments confirmed the dependence of the synthetic activity of protoplasts on the sucrose concentration in PM (Fig. 6). By contrast, control mycelium produced alkaloids when incubated in the absence of sucrose. Microscopic examination of the effect of lowering the sucrose concentration in the medium, by the addition of buffer containing no sucrose, showed that the protoplasts were not approaching lysis at a concentration of 


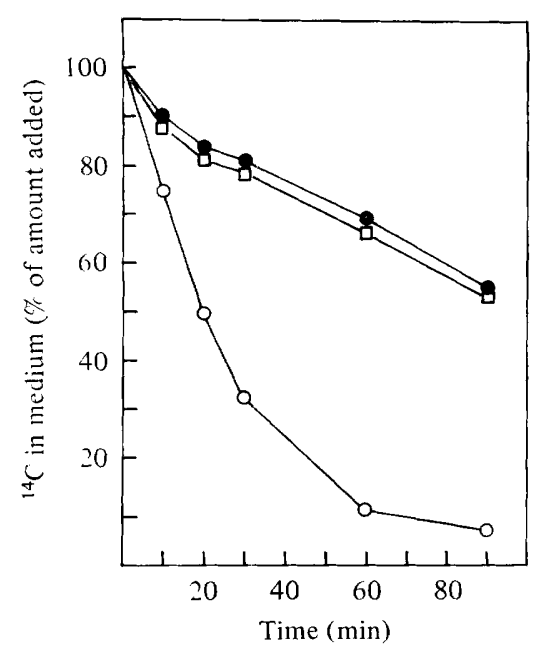

Fig. 5

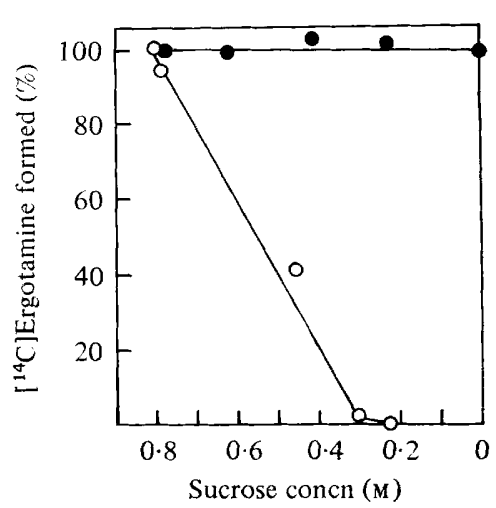

Fig. 6

Fig. 5. Uptake of $\left[{ }^{14} \mathrm{C}\right]$ phenylalanine $(1 \mu \mathrm{Ci})$ by suspensions of protoplasts $(\Theta)$, control mycelium (O) and fresh mycelium ( $\square$ ).

Fig. 6. Dependence of synthetic activity of protoplasts $(O)$ and control mycelium $(O)$ on sucrose concentration in medium PM.

Table 2. Effect of various reagents on ergotamine synthesis in protoplasts and control mycelium of $C$. purpurea

Protoplast suspensions contained 1.66 mM-D-lysergic acid and mycelial suspensions contained $0.5 \mathrm{~mm}-\mathrm{D}$-lysergic acid. Ergotamine synthesis was monitored by measuring the incorporation of $\left[{ }^{14} \mathrm{C}\right]$ phenylalanine as described in Methods.

$\begin{array}{lcccc} & \begin{array}{c}\text { Tryptophan } \\ \text { added } \\ \text { (mM) }\end{array} & \begin{array}{c}{ }^{14} \text { C] Ergotamine } \\ \text { formed } \\ \text { (c.p.m.) }\end{array} & \begin{array}{c}\text { Methionine } \\ \text { added } \\ \text { (mM) }\end{array} & \begin{array}{c}{ }^{14} \text { C]Ergotamine } \\ \text { formed } \\ \text { (c.p.m.) }\end{array} \\ \text { Protoplasts } & 0 & 4000 & 0 & 4000 \\ & 1.66 & 2985 & 1.66 & 3590 \\ \text { Control mycelium } & 10 \cdot 00 & 1823 & 10 \cdot 00 & 1847 \\ & 0 & 7210 & 0 & 7210 \\ & 0 \cdot 5 & 3250 & 0.5 & 5040 \\ & 3.0 & 900 & 3 \cdot 0 & 2540\end{array}$

$0 \cdot 3 \mathrm{M}$-sucrose, but lowering the sucrose concentration caused a gradual swelling until a concentration of $0.1 \mathrm{M}$-sucrose was reached; below this concentration partial lysis was observed. Swelling of the protoplasts was accompanied by an increase in the size of the vacuoles.

Keeping the protoplasts over prolonged periods ( 1 to 2 days) at room temperature also caused swelling. Parallel with the swelling of the whole cells there was an enormous increase in the size of the vacuoles within the protoplasts so that finally the vacuoles almost filled the whole cellular space leaving only a small border between vacuole and cytoplasmic membrane containing the cytoplasmic contents and more or less condensed lipid granules.

\section{DISCUSSION}

Claviceps purpurea (ATCC 20102) is sensitive to the action of snail enzymes, in contrast to other Claviceps strains tested in our laboratory. Normally, fungal protoplasts are prepared from young mycelium, which is more sensitive to the action of lytic enzymes than old mycelium (Villanueva \& Archa, 1971). However, this was not necessary with strain ATCC 
20102 which was therefore particularly suitable for the preparation of protoplasts from mycelium in the stationary growth phase, during which ergot peptide synthesis occurs.

It has been reported previously that mycelium of $C$. purpurea during the late stages of fermentation shows considerable vacuolation (Arcamone, 1977; Vořišek \& Řeháček, 1978). This was also shown to be the case for $C$. purpurea ATCC 20102. When such mycelium was lysed by the action of snail enzyme most of the protoplasts were highly vacuolated and could easily be isolated because of their low density. De Vries \& Wessels (1975) described a similar behaviour for protoplasts of Schizophyllum commune. These authors, however, found that the vacuolated state of the protoplasts was caused by aeration of the mycelium during protoplast preparation. Under anaerobic conditions the appearance of vacuoles was reduced. In the case of $C$. purpurea protoplasts such a dependence was not observed since, in either static or shaken preparations, the percentage of floating vacuolated protoplasts was constant and the vacuolated state is therefore a characteristic of the culture and not a consequence of the preparation procedure.

Amici et al. (1967) reported that $C$. purpurea synthesized considerable amounts of lipid during fermentation and that synthesis proceeded concomitantly with the increase in alkaloid content of the culture. It therefore seems reasonabie to assume that the lipid content of the protoplasts accounts for their low density. In the vacuolated protoplasts we frequently observed relatively large lipid inclusions or a number of smaller granules which could be stained with Sudan IV. The vacuoles were not stained by this treatment. The lipid inclusions and vacuoles are therefore distinct structures. Indeed, they behave differently within the protoplasts, with the vacuoles, but not the lipid inclusions, swelling as the protoplasts swell.

Characteristically, only the floating vacuolated protoplasts were capable of synthesizing ergot peptides and hence it can be assumed that the synthetic capacity is a feature of this special physiological state. As age-dependent vacuolation is accompanied by an increase in the oxidative metabolism of the cell it is not surprising that ergot peptide synthesis is stimulated by shaking, in both the protoplast and mycelial suspensions. Furthermore, it was noted that the process of preparing the protoplasts rendered the control mycelium more active than fresh mycelium. Since protoplast medium (PM) lacks a nitrogen-source, but otherwise resembles the culture medium in its composition, we propose that the protoplasts and control mycelium represent nitrogen-starved cells. Further support for this assumption comes from the finding that supplying the cells with ammonium ions during the protoplast preparation lowered their synthetic capacity (U. Keller \& R. Zocher, unpublished results). The protoplasts were less active than the control mycelium but as active as the fresh mycelium in uptake, which indicates that the transport systems are most efficient when an intact wall structure is present. The rate of uptake was high enough to allow the penetration of sufficient quantities of all precursors of ergotamine and ergocryptine into the cells. The different incorporation ratios of $\left[{ }^{14} \mathrm{C}\right]$ phenylalanine, $\left[{ }^{14} \mathrm{C}\right]$ alanine and $\left[{ }^{14} \mathrm{C}\right]$ proline into ergotamine suggests that these compounds are subject to isotope dilution by the amino acids of the internal pool. Measurement of the amino acid pool of the protoplasts supports this conclusion. Such effects could not be observed in the case of ergocryptine. Only $\left[{ }^{11} \mathrm{C}\right]$ valine was incorporated into this alkaloid in the presence of D-lysergic acid and further experimentation is necessary to explain the difference between ergotamine and ergocryptine synthesis. A common feature in the formation of the two compounds is that D-lysergic acid acts as a stimulator when added externally. Since, of all precursors added, only D-lysergic acid stimulated ergotamine and ergocryptine synthesis we propose that the concentration of this compound in the cells is a rate-limiting factor in ergot peptide synthesis. The relative extent of stimulation is higher in protoplasts than in control mycelium and a possible explanation of this finding is that the endogenous D-lysergic acid concentration in protoplasts is very low but in the control mycelium is high.

Although tryptophan and methionine serve as precursors of the ergoline-ring of D-lysergic acid (Floss, 1976), addition of the compounds to protoplasts or mycelium led to a decrease 
in ergotamine synthesis in the cells. This effect was also observed when D-lysergic acid was present during these experiments. Since the inhibitory effect was observed in the presence and absence of D-lysergic acid, the inhibition must take place at the stage of peptide synthesis and not at that of ergoline-ring synthesis. The reason for this effect is not known but a similar effect was observed in Streptomyces antibioticus, where actinomycin synthesis is inhibited by tryptophan or methionine (Keller \& Kleinkauf, 1977; Salzman et al., 1969). In both organisms, methionine was the amino acid of lowest concentration in the cell (Keller, 1977). This may indicate a regulatory role of this amino acid in the control of the biosynthesis of the two secondary metabolites.

Results suggest that ergotamine synthesis in protoplasts and mycelium of $C$. purpurea ATCC 20102 is dependent on the actual concentrations of the free precursor constituents in the cellular pool. A similar conclusion was reached recently by Beacco et al. (1978) during their studies concerning the incorporation of analogues of phenylalanine into ergot peptides by $C$. purpurea. However, it is not clear whether this pool is the cytoplasmic amino acid pool itself or whether it is located in a cell compartment, such as the vacuole. Location of these pools would enable the determination of the intracellular locus of ergotamine synthesis. We have not yet been able to make a homogeneous vacuole preparation from $C$. purpurea protoplasts but are currently working on this problem and hope that the protoplast system will eventually provide a cell-free system of ergot alkaloid synthesis.

It is our pleasure to acknowledge the excellent technical assistance of Mrs K. Rehberg. We are also indebted to Professor G. Kraepelin for valuable discussions and to Dr K. Kieslich of Schering AG, Berlin, for kindly supplying us with various Claviceps strains. This work was supported by grant K1 148/16 of the Deutsche Forschungsgemeinschaft.

\section{REFERENCES}

Amici, A. M., Minghetti, A., Scotti, T., Spalla, C. \& Tognoli, L. (1966). Production of ergotamine by a strain of Claviceps purpurea (Fr.) Tul. Experientia 22, 415-416.

Amici, A. M., Minghetti, A., Scotti, T., Spalla, C. \& Tognoli, L. (1967). Ergotamine production in submerged culture and physiology of Claviceps purpurea. Applied Microbiology 15, 597-602.

Amici, A. M., Minghetti, A., Scotti, T., Spalla, C. \& ToGNOLI, L. (1969). Production of peptide ergot alkaloids in submerged culture by three isolates of Claviceps purpurea. Applied Microbiology 18, 464 468.

Arcamone, F. (1977). In Biologically Active Substances - Exploration and Exploitation, pp. 49-77. Edited by D. A. Hems. Chichester: Wiley.

Bassett, R. A., Chain, E. B. \& Corbett, K. (1973). Biosynthesis of ergotamine by Claviceps purpurea (Fr.) Tul. Biochemical Journal 134, 1-10.

Beacco, E., Bianchi, M. L., Minghetti, A. \& Spalla, C. (1978). Directed biosynthesis of analogues of ergot peptide alkaloids with Claviceps purpurea. Experientia 34, 1291-1293.

BraY, G. (1960). A simple efficient liquid scintillator for counting aqueous solutions in a liquid scintillation counter. Analytical Biochemistry 1, 279285.

De Vries, O. M. H. \& Wessels, J. G. H. (1975). Chemical analysis of cell wall regeneration and reversion of protoplasts from Schizophyllum commune. Archives of Microbiology 102, 209218.
Floss, H. G. (1976). Biosynthesis of ergot al ka loid and related compounds. Tetrahedron 32, 873-912.

Gröger, D. (1975). Biosynthese des Peptidteils der Mutterkornalkaloide vom Cyclol-Typ. Planta medica 28, 37-51.

Gröger, D. \& SajdL, P. (1972). Enzymatic conversion of chanoclavine-I. Pharmazie 27, 188.

Gröger, D., Johne, S. \& HÄrtling, S. (1974). On the metabolism of oligopeptides and diketopiperazine in Claviceps species. Biochemie und Physiologie der Pflanzen 166, 33-43.

Heinstein, P. F., Lee, S.-L. \& Floss, H. G. (1971). Isolation of dimethylallylpyrophosphate:tryptophan dimethylallyltransferase from ergot fungus. Biochemical and Biophysical Research Communications 44, 1244-1251.

KELLER, U. (1977). Studien zur Biosynthese des Actinomycins in Streptomyces antibioticus. Dissertation, Technische Universität Berlin, F.R.G.

Keller, U. \& KleinKauf, H. (1977). Studies of the biosynthesis of actinomycin in protoplasts from Streptomyces antibioticus. Archives of Biochemistry and Biophysics 184, 111-124.

Salzman, L., Weissbach, H. \& Katz, E. (1969). Enzymatic synthesis of actinocyl peptides. Archives of Biochemistry and Biophysics 130, 536-546.

Spalla, C., Guicciardi, A., Marnati, M. P. \& Oddo, N. (1976). In Abstracts of the Fifth International Fermentation Symposium, p. 192. Edited by $H$. Dellweg. Berlin: Experimental College for Alcohol Production and Fermentation Technology of the Institute of Fermentation and Technology 
Stahl, C. H., Neumann, D., Schmauder, H.-P. \& Voǩıšex, J. \& ŘeháčeK, Z. (1978). Fine-structural GRÖGER, D. (1977). Preparation of protoplasts from Claviceps. Biochemie und Physiologie der Pflanzen 171, 363-368.

localization of alkaloid synthesis in endoplasmic VillanUEVA, J. R. \& ARCha, I. G. (1971). Methods reticulum of submerged Claviceps purpurea. in Microbiology 4, 665-718. 